\title{
Víctimas, derechos y transición a la Paz: precedentes jurisprudenciales en Colombia
}

\author{
Lilibeth García Henao*
}

\section{RESUMEN}

En el presente artículo presentó resultados parciales del Proyecto de Investigación "El Derecho de las víctimas, en el marco del proceso de justicia transicional que vive Colombia; evaluación de un paradigma", adscrito al Grupo de Investigación en "Derechos Humanos, Derecho Penal y Garantías Procesales"1, dentro de la línea titulada "Derechos Humanos, Derecho Internacional Humanitario, Derecho Penal Internacional'. El énfasis está en los precedentes jurisprudenciales de los derechos de las víctimas de nuestro conflicto armado dentro de los últimos 10 años hasta la actualidad, y al mismo tiempo, el cambio de orientación de la doctrina de la Corte Constitucional de Colombia, al ponerse a tono con los más elevados estándares de administración de justicia a nivel internacional y con la más moderna jurisprudencial y doctrina constitucional en Derechos Humanos. Ahora bien, la situación actual de las víctimas de estos hechos atroces ha sido caracterizada, en términos generales, por la limitada protección judicial de sus derechos, teniendo en cuenta que las organizaciones criminales y grupos ilegales al margen de la ley, no sólo obedecen a una estructura jerarquizada compleja, sino que han adoptado un modus operandi trasnacional y más actual, dado que al

\footnotetext{
* García, Henao Lilibeth. Abogada, de la Universidad del Norte de Barranquilla- Colombia, Magister en Estudios Político-Económicos de la misma Universidad, Perfeccionamiento en Manejo y Solución de Conflictos e Investigador Científico en Ciencias Sociales, Humanas y Jurídicas. Actualmente Docente Investigador en Derecho Internacional de los Derechos Humanos y DIH, de la Universidad Libre de Bogotá Colombia, adscrita al Grupo de Investigación de Derechos Humanos, Derecho Penal y Garantías Procesales de la Facultad de Derecho de la Universidad Libre, E-mail: Igarciahenao@gmail.com, Calle 8a No 5-75 La Candelaria. Tel 0057-1-314-2245880, Bogotá- Colombia, Noviembre del 2010. ®Sitio web Investigadora Principal: Bogotá D.C. - Colombia-2010, Universidad Libre-Facultad Derecho http://201.234.78.173:8081/cvlac/visualizador/generarCurriculoCv.do?cod_rh=0000143090

1 Sitio Web del Grupo de Investigación: Derechos Humanos, Derecho Penal y Garantías Procesales - Bogotá D.C. - Colombia-2010, Universidad Libre-Fac. Derecho Bhttp://201.234.78.173:8080/gruplac/jsp/visualiza/visualizagr.jsp?nro=00000000001813
} 
igual que con la evolución de la humanidad y el avance tecnológico, estos también han evolucionado en sus métodos de hacer la guerra, financiación y demandas. En este sentido es pertinente señalar lo mucho que un país como Colombia ha avanzado en materia de tolerancia, perdón y reconciliación, e igualmente es mucho lo que nos falta con referencia a la proporcionalidad del daño y el castigo o sanción.

\section{PALABRAS CLAVE}

Precedente, Víctima, Jurisprudencia, Reparación, Justicia, Responsabilidad.

\section{ABSTRACT}

In this article I present partial results of "Project Investigation The Victims' Rights, in the framework of the Transitional Justice in Colombia, Evaluation of a Paradigm" attached to the Research Group on Human Rights, Criminal Law and Procedural Safeguards Within the line entitled "Human Rights, International Humanitarian Law, International Criminal Law. " The emphasis is on case law concerning the rights of victims of our armed conflict within the last 10 years now, and at the same time, the shift of the doctrine of the Constitutional Court of Colombia, to catch up with the highest standards of justice at international level and with the latest case law and constitutional doctrine on Human Rights. However, the current situation of the victims of these atrocities has been characterized in general by the limited legal protection of their rights, given that criminal organizations and illegal armed groups outside the law, not only obey complex hierarchical structure, but have adopted a modus operandi and more transnational today, as well as with the evolution of humanity and technological advancement, they have also evolved in its methods of waging war, funding and demands. In this regard it is pertinent to note how much a country like Colombia has made progress in terms of tolerance, forgiveness and reconciliation, and also is much that is what we lack reference to the proportionality of the harm and the punishment or penalty.

\section{KEYWORDS}

Previous Victim, Court, Repair, Justice, Responsibility. 


\section{INTRODUCCIÓN}

Abordar cualquier tema referente a la problemática de las víctimas en Colombia con ocasión de los procesos de desmovilización, desarme y reinserción de los grupos insurgentes, supone plantear una reflexión acerca de las dimensiones conceptuales que se han dado a la definición de Justicia Transicional a partir de los precedentes jurisprudenciales en materia de víctimas en Colombia frente al proceso de transición hacia la paz y al modelo de justicia penal en materia de justicia restaurativa. Si bien es cierto que dentro de las diferentes aproximaciones teóricas que se han acogido, estas encierran tres principios fundamentales cuales son:

1. El derecho de las víctimas a conocer la verdad

2. El derecho de las víctimas a la reparación

3. El Derecho de las víctimas a que se haga justicia

También es cierto que estas tres dimensiones en la conceptualización suponen un marco jurídico, político y ético, el cual se caracteriza por todos aquellos procesos a través de los cuales se realizan transformaciones radicales de un orden social y político, ya sea de un régimen dictatorial a uno democrático, o bien por la finalización de un conflicto interno armado y la consecución de la paz.

Dicho esto, es pertinente anotar de acuerdo con Uprimny Yepes, R. (2006) [...]... "Que los procesos de justicia transicional enfrentan importantes dilemas, originados todos en la compleja necesidad de equilibrar los objetivos contrapuestos de justicia y paz, acerca de la manera como deben ser enfrentadas las violaciones masivas de derechos humanos en el marco de los Procesos de Paz" [...] dado que este reviste gran complejidad, pues posee dimensiones jurídicas, políticas y éticas, que suelen presentar profundas tensiones entre sí. Estas tensiones se concretan en el enfrentamiento entre los imperativos jurídicos internacionales, que muestran una tendencia hacia la exigencia del castigo de los responsables de crímenes atroces, por un lado, y las restricciones derivadas de 
las realidades políticas y de la necesidad de lograr negociaciones exitosas para trascender el conflicto, por otro lado.

Si bien es cierto que el desarrollo exitoso de un proceso de desmovilización, desarme y paz de actores involucrados en un conflicto armado interno y prolongado, que aspire a la no repetición de "crímenes del Derecho Internaciona"l, expresión que fue adoptada por el Relator Especial Cherif Biassiouni en su informe final presentado en virtud de la Resolución 1999/33 de la Comisión de Derechos Humanos sobre "El derecho de restitución, indemnización y rehabilitación de las víctimas de las violaciones graves de los Derechos Humanos y las libertades fundamentales" en los "Principios y directrices básicos sobre el Derecho de las víctimas de violaciones de las normas internacionales de derechos humanos y de derecho internacional humanitario a interponer recursos y obtener reparaciones". Naciones Unidas, Consejo Económico y Social, 2000; y de violaciones de los derechos humanos e infracciones graves al Derecho Internacional Humanitario, necesariamente supone que, las expectativas realistas de convivencia pacífica bajo el imperio de la ley, deben basarse en medidas que hagan frente a los desafíos planteados por la construcción de una cultura de tolerancia y rechazo a la impunidad.

Internacionalmente se han adoptado principios y normas en materia de verdad, justicia y reparación con el propósito de que los pueblos tengan la posibilidad de edificar la paz y construir la reconciliación sobre bases justas, firmes y duraderas. La paz y la reconciliación no pueden estar fundadas ni en el olvido de los crímenes, ni en la impunidad e indulgencia hacia los criminales, y menos aún en el menosprecio por las víctimas.

\section{PROBLEMA}

Uno de los efectos más graves e inmediatos de la violencia a gran escala de los conflictos armados internos consiste en lo que se conoce como la invisibilización 
de las víctimas. Entendiendo por víctima para efectos de esta investigación, "la persona que, individual o colectivamente, como resultado de actos u omisiones que violan las normas internacionales de Derechos Humanos o del Derecho Internacional Humanitario, hayan sufrido daños, inclusive lesiones físicas o mentales, sufrimientos emocionales, pérdida financiera o menoscabo sustancial de sus derechos fundamentales. También se considera víctima, a los miembros de la familia directa o personas a cargo de la víctima directa, así como a las personas que, al intervenir para asistir a la víctima o impedir que se produzcan otras violaciones, hayan sufrido daños físicos, mentales o económicos", conforme como lo ha definido el Comité Internacional de los Derechos Humanos en su Informe final del Relator Especial Cherif Biassiouni en el 2000 de la ONU y el Consejo Económico y Social del mismo organismo internacional.

Y por "invisibilización", la concebiremos como un borramiento de hecho y de derecho de los sujetos a través de mecanismos de supresión de la identidad, comportamiento que está dirigido a destruir grupos humanos con características propias, dado que el propósito de un proceso de invisibilización apunta a destruir la memoria histórica de un grupo específico, lo que produce un daño a la identidad individual y social" (Sentencia C-914, 2010), y por ello los invisibilizados reconstruyen una memoria que no afecte su supervivencia, con una nueva identidad ante otros para no ser agredidos aún más. Afecta por doble vía: por un lado, la impuesta; por otro, la que los individuos o grupos culturales deben imponerse como un deber de sobrevivencia, es decir, "desaparecer para seguir estando", en este proceso van quedando rabias, resentimientos, dolores, y en general afectaciones que van haciendo cada vez más una carrera hacia la invisibilización. Paradójicamente la única forma en la que las víctimas de los distintos actos de violencia logran construir una relación con el Estado y un reconocimiento por parte del mismo, es a partir de su condición de víctima, y no por su condición de sujeto de derechos, ni de ser humano con dignidad. 
Ahora bien, continuando con la idea central del problema de investigación, decíamos que uno de los efectos más graves e inmediatos de la violencia a gran escala de los conflictos armados internos, consiste en lo que se conoce como la invisibilización de la víctimas y la ausencia de recursos efectivos para lograr la intervención de las instituciones del Estado que ha venido dejando a la población víctimas del conflicto, en términos de alta vulnerabilidad frente a los actores armados que aplican estrategias que generan y hacen mucho más agudo el problema del desplazamiento forzado, dificultando el esclarecimiento de lo sucedido y la administración de justicia.

La aplicación de la ley de justicia y paz, en el marco del proceso de desmovilización y desarme de los grupos insurgentes que ha venido viviendo Colombia en los últimos años, plantea varios interrogantes, como:

¿Hasta qué punto pueden conciliarse las concesiones por parte del Estado a los desmovilizados, frente a las pérdidas de las víctimas, tanto en, lo económico, jurídico, político y social? Es decir, las amplias concesiones, perdón, amnistías o indultos, etc.,

¿En qué medida ha venido siendo una real transición hacia la democracia y la paz, dentro de un Estado de Derecho informado por la más moderna doctrina constitucional en materia de Derechos Humanos y de Derecho Internacional Humanitario? O, ¿Será que se están dejando semillas de resentimiento y violencia en las víctimas que no han sentido que se les haya propinado un real castigo a los violadores de los Derechos Humanos y del Derecho Internacional Humanitario?

Si bien es cierto, que en las siguientes líneas, el énfasis está en los precedentes jurisprudenciales del Derecho de las víctimas y perjudicados en el proceso penal; también es cierto el aspecto de carácter sociológico y político referente a los anteriores interrogantes, que incuestionablemente son de una gran riqueza 
jurídica, ética, política y social, para otra reflexión, que en este momento no me ocupa.

\section{METODOLOGÍA}

La construcción de uno o varios precedentes jurisprudenciales no es una improvisación del intérprete o el investigador, en consecuencia con la técnica descriptiva de investigación jurídica, y a la luz del método de interpretación sociológica, aproximaré los lineamos en materia de los derechos de las víctimas en el marco del proceso de justicia transicional en Colombia.

El método sociológico, parte de la tesis de que el derecho es un producto social y como tal no indiferente a la relación social que regula. Su principal exponente es el jurista francés François Geny, quien en su obra "Método de interpretación y fuentes del derecho privado positivo" plantea sus principios esenciales cuales son:

a. Cuando un aspecto jurídico no puede ser solucionado con las fuentes formales, es necesario que el intérprete e investigador crea o elabore por sí mismo el principio. Aquí, el juez tiene la facultad y la libertad en función de la realidad social impetrada de crear la norma como lo haría el legislador.

b. Cuando la ley positiva carece de eficacia, la costumbre, la autoridad y la tradición deben llenar el vacío, buscando siempre regular con equidad la situación concreta escapada de la norma positiva.

En cuanto al procedimiento a seguir, Geny expresa que hay dos posibilidades:

a. La interpretación por la fórmula del texto y,

b. La interpretación con la ayuda de elementos independientes de la fórmula, esto es, trabajos preparatorios, antecedentes históricos, ideas reinantes, dinámica social, legislación comparada etc. 
A partir del método sociológico, he logrado construir la conceptualización de "víctima" en el marco del Paradigma de Justicia Restaurativa en lo penal y de Justicia Transicional como una política de Estado dentro del proceso de desmovilización, desarme y reinserción que Colombia ha vivido, sin perjuicio de no perder de vista que aun no somos una sociedad post-conflicto. Ahora bien, hay que tener presente las diferencias estructurales acerca de los dos paradigmas Justicia Restaurativa y Justicia Transicional a fin de no incurrir en equívocos, de tal suerte que es necesario ilustrar este desarrollo con los soportes hermenéuticos que estructuran los precedentes en la materia, y que a su vez brindan fortalecimiento de la Línea Jurisprudencial.

\section{El derecho de las víctimas a la verdad y a la justicia}

El derecho a la verdad es la que le asiste a las víctimas y a la sociedad Colombiana con el ánimo de conocer la realidad con el propósito de construir la memoria histórica como garantía de la no repetición de los mismos actos violentos para así iniciar diferentes procesos, tendientes a fortalecer una cultura de perdón y tolerancia que se concilie con las tensiones que plantea la Ley de Justicia y Paz dentro del marco del proceso de Justicia Transicional que vive nuestro país. La comunidad internacional ha identificado una serie de lineamientos en materia de verdad, justicia y reparación y sobre todo en materia de responsabilidad civil y penal bien delineadas y definidas, que se nutren tanto de las experiencias vividas en distintas sociedades como en los principios de derecho reflejados en la obligación de los Estados de administrar justicia conforme al derecho internacional.

En los últimos dos años y en gran medida tomando en cuenta la evolución de la normatividad internacional sobre el tema, la Corte Constitucional modificó su doctrina sobre los derechos de las víctimas en el proceso penal; es así, como la más autorizada doctrina y jurisprudencia internacional en Derechos Humanos ha concluido que los derechos de las víctimas desbordan el campo indemnizatorio, 
pues incluyen el derecho a la verdad de lo ocurrido y una justicia de carácter penal, mediante la cual se castigue a los causantes del daño, dolor y perdida de las víctimas. Para efectos de lo dicho se puede revisar la Sentencia 161 del 2008, mediante la cual se solicita que la corte declare la inconstitucionalidad de los artículos 95 (parcial) de la Ley 599 de 2000 (Código Penal) y 102 (parcial) de la Ley 906 de 2004, que hacen referencia a la salvaguarda del derecho la verdad, justicia y reparación de las víctimas.

Particular importancia tiene en este aspecto la sentencia del 14 de marzo de 2001 de la Corte Interamericana de Derechos Humanos, con referencia del Caso Barrios Altos (Chumbipuma Aguirre y otros c. Perú), en donde ese Tribunal decidió que las leyes de amnistía peruanas eran contrarias a la Convención Interamericana y que el Estado era el responsable por violar el derecho de las víctimas a conocer la verdad sobre los hechos y a obtener justicia en cada caso, y a pesar de que dicho Estado había aceptado su responsabilidad y había decidido otorgar un reparación material a las víctimas.

Ahora bien, la evolución que se observa en la doctrina y la jurisprudencia sobre los derechos de las víctimas tiene una evidente relevancia constitucional, pues los derechos constitucionales deben ser interpretados de conformidad con los Tratados de Derechos Humanos ratificados por Colombia (C.P. Art. 93). Esto significa que, el inciso segundo del artículo 93-2 "Constitucionaliza todos los tratados de derechos humanos ratificados por Colombia y referidos a Derechos que ya aparecen en la Carta y en virtud de la regla hermenéutica sobre favorabilidad, el intérprete debe escoger y aplicar la regulación que sea más favorable a la vigencia de los Derechos Humanos" (Uprimny Yepes, 2001).

En varias oportunidades, la Corte Constitucional también ha indicado que la jurisprudencia de las instancias internacionales de derechos humanos constituye una pauta relevante para interpretar el alcance de los tratados y por ende de los propios derechos constitucionales; por ello, la doctrina de la Corte Interamericana 
sobre los derechos de las víctimas debe ser valorada internamente por las autoridades Colombianas en general, y por la jurisprudencia de la Corte Constitucional en particular como las sentencias C-10 de 2000, T-1319 de 2001 y C-228 de 2002, fundamento 6.3.

En ese sentido, la Corte Constitucional ha concluido que la Carta Política de 1991 reconoce a las víctimas y perjudicados por un hecho punible unos derechos que desbordan el campo de la reparación económica, pues incluyen también el derecho a conocer la verdad y a que se haga justicia. De tal suerte que ha señalado que "las víctimas de los delitos tienen un derecho a la verdad y a la justicia, que desborda el campo de la simple reparación, tal y como lo ha señalado con claridad la doctrina internacional en materia de derechos humanos, que es relevante para interpretar el alcance de los derechos constitucionales (C. P., Art. 93 y Sentencia T-1267 de 2001).

En consecuencia, la Corte Constitucional ha venido sintetizando su doctrina de la siguiente manera:

[...]... La víctima y los perjudicados por un delito tienen intereses adicionales a la mera reparación pecuniaria. Algunos de ellos han sido protegidos por la Constitución de 1991 y se traducen en tres derechos relevantes:

i. El Derecho a la Verdad, esto es la posibilidad de conocer lo que sucedió y en buscar una coincidencia entre la verdad procesal y la verdad real. Este derecho resulta particularmente importante frente a graves violaciones de Derechos Humanos, en concordancia con la Sentencia del 14 de Marzo del 2001 de la Corte Interamericana de Derechos Humanos, donde la Corte resalta como contrarios a la Convención Americana aquellos instrumentos legales desarrollados por los Estados partes que le nieguen a las víctimas su derecho a la verdad y a la justicia. 
ii. El derecho a que se haga justicia en el caso concreto, es decir, el derecho a que no haya impunidad.

iii. El derecho a la reparación del daño que se le ha causado, a través de una compensación económica, que es la forma tradicional como se ha resarcido a la víctima de un delito........] (Sentencia C-282 de 2002).

Es pertinente aclarar que la Corte no se ha limitado a formular la anterior doctrina sobre los derechos de las víctimas y perjudicados por hechos punibles sino que, además, dicha doctrina ha constituido la base para que la jurisprudencia de la Corte Constitucional ampare los derechos de las víctimas, tanto en casos de tutela como en procesos de control constitucional.

Igualmente vale aclarar que no existe ninguna duda sobre el reconocimiento e importancia que tienen los derechos de las víctimas en el ordenamiento constitucional colombiano, y más aún en un Estado Social de Derecho, que consagra como principios medulares la búsqueda de la justicia (CP. Art. 229), "el derecho procesal penal no solo debe regular y controlar el poder sancionador del Estado en beneficio del acusado -esto es en función de quien padece el procesosino que debe también hacer efectivos los derechos de la víctima-esto es de quien ha padecido el delito", puesto que "la víctima es verdaderamente la encarnación viviente del bien jurídico que busca ser protegido por la política criminal." Detallado en el Caso Velázquez Rodríguez, sentencia 29 de Julio de 1988Corte Interamericana de Derechos Humanos.

\section{El non bis in idem}

Este principio a veces llamado res judicata, ha sido incorporado a la normativa internacional por medio del artículo 14(7) del PIDCP y del artículo 8(4) de la Convención Americana. 
Y si bien es cierto que a los derechos de las víctimas corresponden ciertas obligaciones del Estado; pues si las víctimas tienen derecho no solo a ser reparadas sino además a saber qué ocurrió y a que se haga justicia, entonces el Estado tiene el deber correlativo de investigar seriamente los hechos punibles. Esta obligación estatal es tanto más intensa cuanto más daño social haya ocasionado el hecho punible. $\mathrm{Y}$ por ello ese deber estatal adquiere particular fuerza en los casos de violaciones de derechos humanos. De tal suerte, que con lo señalado por la Corte Interamericana con criterios que comparte con la Corte Constitucional Colombiana, "que las personas afectadas por conductas lesivas de los derechos humanos tienen derecho a que el Estado investigue esos hechos, sancione a los responsables y restablezca, en lo posible, a las víctimas en sus derechos" (Sentencia C-004/03 y Sentencia C-228/02 de Corte Constitucional, y Caso Loayza Tamayo Vs. Perú Sentencia de fondo del 17 de septiembre de 1997).

Según el Alto Tribunal Internacional, si el aparato del Estado actúa de modo que una conducta lesiva de los derechos humanos "quede impune o no se restablezca, en cuanto sea posible a la víctima en la plenitud de sus derechos, $y$ puede afirmarse que ha incumplido en el deber de garantizar su libre y pleno ejercicio a las personas sujetas a su jurisdicción." En consecuencia, ha concluido la Corte Interamericana con palabras plenamente válidas en el Constitucionalismo Colombiano:

[...] En ciertas circunstancias puede resultar difícil la investigación de hechos que atentan contra derechos de la persona. La de investigar es, como la de prevenir, una obligación de medio o de comportamiento que no es incumplida por el solo hecho de que la investigación no produzca un resultado satisfactorio. Sin embargo, debe emprender con seriedad y no como una simple formalidad condenada de antemano a ser infructuosa. Debe tener un sentido y ser asumida por el Estado como un Deber Jurídico Propio y no como una simple gestión de intereses particulares que dependen de la iniciativa procesal de la víctima o de 
sus familiares o de la aportación privada de elementos probatorios, sin que la autoridad pública busque efectivamente la verdad. Esta apreciación es válida cualquiera que sea el agente al cual puede eventualmente atribuirse la violación, aun los particulares, pues, si sus hechos no son investigados con seriedad, resultaría, en cierto modo, auxiliador por el poder público, lo que comprometería la responsabilidad internacional del Estado... [...]

El deber de investigar del Estado, con referencia a los hechos punibles y los derechos constitucionales de las víctimas que se encuentra íntimamente ligado al deber de las autoridades de asegurar la vigencia de un Orden Justo (CP, Preámbulo y Art. $2^{\circ}$ ), no son tampoco absolutos, y por ello no pueden ser invocados para arrasar con la seguridad jurídica de rango constitucional (CP, Art 29 y 150); se debe encontrar un justo medio a fin de ponderar esos derechos y valores en conflicto, y tomar decisiones políticas que intenten armonizarlos, tanto como sea posible; de tal manera que las decisiones legislativas estén sujetas a un control constitucional, pues corresponde a la Corte Constitucional examinar si esa ponderación adelantada por el legislador al expedir las normas penales, es proporcionada y respeta el contenido esencial tanto de los derechos de las víctimas como de los derechos del procesado.

Ahora bien, la Corte Constitucional destaca que la discrecionalidad legislativa en esta materia es bastante limitada, pues el derecho penal es un área fuertemente constitucionalizada, tal y como se ha destacado y reiterado ejemplo de ello es la sentencia C-038 de 1995. Las consideraciones anteriores han permitido concluir que, dentro de ciertos límites: "La ley podrá relativizar el non bis idem, a fin de favorecer los derechos de las víctimas. Pero que igualmente podrá el legislador optar por reforzar la garantía del non bis ídem, incluso si dicha decisión implica una relativización de los derechos de las víctimas. Es más, un examen de derecho comparado muestra que ciertos países como Estados Unidos optan por el segundo modelo y tienden a consagrar en forma casi absoluta la prohibición de doble enjuiciamiento, mientras que otros ordenamientos jurídicos han relativizado 
esa garantía del procesado, a fin de favorecer otros bienes y derechos constitucionales."

\section{Precedentes jurisprudenciales referentes a la parte civil y a la víctima}

La antigua visión de la parte civil interesada exclusivamente en la búsqueda de una reparación económica dentro del proceso penal, fue recogida por la Corte Constitucional en la Sentencia C-293/95. A pesar de que esa sentencia fue objeto de cuatro salvamentos de voto en el sentido de acoger una concepción constitucional amplia del ámbito de la parte civil, la doctrina allí sentada fue reiterada por las sentencias C-475 de 1997, SU-717 de 1998, C-163 de 2000, y C1711 de 2000, 394 del 2007, Sentencia 1312 del 2009, 936 del 2010 y 906 del 2004.

Ello muestra que se trata de un precedente influyente y respetado que merece un cuidadoso análisis y contiene una interpretación plausible que no puede ser descalificada.

De conformidad con la Sentencia C-293/95, el interés de la parte civil en el proceso penal era esencialmente económico: obtener una indemnización que reparare el daño causado con el delito. Por esa razón se justificaba restringir el ámbito de su participación en una etapa donde aún no había formalmente proceso penal, tal como la investigación previa. Para la Corte, ello era necesario y deseable a fin de impedir que los "actos retaliatorios" de la víctima pudieran llegar a interferir en la investigación y en la definición de la procedencia de la acción penal.

Es importante subrayar que la sentencia C-293/95 definió los derechos de la parte civil a la luz de la legislación vigente y no a partir del texto de la Constitución y dijo lo siguiente:

"Se trata entonces de proponer una acción distinta a la acción civil, dentro del proceso penal, cuya plausibilidad puede discutirse, pero cuya inexistencia no torna 
inexequible a la que si existe con sus finalidades y muy claramente determinadas y sin conflicto alguno con la Constitución. [...] Y no se insista en que la víctima o sus herederos pueden pretender el esclarecimiento de la verdad, al margen de los valores patrimoniales, porque, tal como más atrás quedo dicho, la acción civil tiene en nuestra legislación una finalidad pecuniaria (desde luego legítima), y la ausencia de normas que apuntan a intereses más altos no hacen inexequibles las reglas que la consagran". De tal manera que la premisa de la cual partió la Corte fue que el legislador podía, con gran amplitud, definir los derechos de la parte civil y que, dada la definición entonces vigente restringía a la acción indemnizatoria; además, la Corte reconoció expresamente que el legislador podía variar la definición y los alcances de la institución de la parte civil.

De conformidad con la jurisprudencia de la Corte, para que un cambio jurisprudencial no se considere arbitrario, este debe obedecer a razones poderosas que lleven no sólo a modificar la solución al problema jurídico concreto, sino que prevalezcan sobre las consideraciones relativas al derecho de igualdad y a la seguridad jurídica que invitarían a seguir al precedente (Corte Constitucional, sentencia C-836/01, M.P. Rodrigo Escobar Gil. Aclaración de Voto de Manuel José Cepeda Espinoza y Marco Gerardo Monroy Cabra).

Las razones más pertinentes que la Corte encontró son las siguientes:

i. Un cambio en el ordenamiento jurídico que sirvió de referente normativo para la decisión anterior, lo cual también incluye la consideración de normas adicionales a aquellas tenidas en cuenta inicialmente.

ii. Un cambio en la concepción del referente normativo debido no a la mutación de la opinión de los jueces competentes, sino a la evolución en las corrientes de pensamiento sobre materias relevantes para analizar el problema jurídico planteado.

iii. La necesidad de unificar precedentes por coexistir, desde antes, dos o más líneas jurisprudenciales encontradas. 
iv. La constatación de que el precedente se funda en una doctrina respecto de la cual hubo una gran controversia (Alexy, 1997).

Estas son las razones de peso que han justificado la modificación de la doctrina según la cual la víctima o perjudicado por un delito, solo está interesado en la reparación económica del daño que se le ha ocasionado.

1. Se hace necesario considerar un referente normativo más amplio que el tenido en cuenta en la sentencia C-293/95, en donde la Corte se refirió al valor de la dignidad humana, a la participación, al acceso a la justicia, al monopolio estatal de la acción penal y a la libertad del procesado, como los fundamentos para restringir los intereses de la parte civil dentro del proceso penal y a lo puramente económico.

El referente normativo considerado en la sentencia C-293/95, no incluyó las disposiciones específicas sobre las víctimas, como las normas relativas a la obligación del Fiscal General de proteger a las víctimas y las de adoptar las medidas necesarias para el restablecimiento de sus derechos (Art. 250, numerales 1 y 4, CP.).

Además, el artículo $2^{\circ}$ de la Constitución y disposiciones concordantes, establecen el deber constitucional de las autoridades judiciales de garantizar el goce efectivo de los derechos de las personas dentro de las cuales estén comprendidas las víctimas y perjudicados, son estos referentes normativos los que adquieren plena relevancia.

De tales fundamentos así como de otros principios ya mencionados y subrayados, se deriva que una protección efectiva de los derechos de la víctima requiere que se garantice su acceso a la administración de justicia para buscar la verdad, la justicia y la reparación. 
2. Ha habido un cambio en la concepción del referente normativo, en particular en el Derecho Internacional de los Derechos Humanos. En 1995, fecha en que se produjo la sentencia 293, aún no se había cristalizado la tendencia del derecho internacional -en especial en el derecho de los derechos humanos del sistema interamericano- hacia una protección amplia de los derechos de las víctimas de graves violaciones de los derechos humanos.

En el año 2001, La Corte Interamericana de Derechos Humanos señaló que las medidas legislativas que impidieran a las víctimas de violaciones de los Derechos Humanos conocer la verdad de los hechos, resultaban contrarias a la Convención Americana de Derechos Humanos. Como quiera que según el artículo 93 constitucional, "los derechos deben ser interpretados de conformidad con los Tratados Internacionales sobre derechos humanos ratificados por Colombia", es necesaria que la doctrina de la Corte interamericana de Derechos Humanos, sea valorada por la jurisprudencia de la Corte Constitucional.

Si bien los cambios en la concepción de los derechos de las víctimas y los perjudicados se refieren a graves violaciones de los derechos humanos, la tendencia en las legislaciones internas no se limita a dicha protección mínima sino que comprende también delitos de menor gravedad. Igualmente el legislador Colombiano dispone de un margen de apreciación para modular el alcance de los derechos de la parte civil según diferentes criterios - dentro de los cuales se destacan, de un lado, la gravedad del delito, y del otro, la situación del procesado que puede llegar a ser de una significativa vulnerabilidad- siempre que no reduzca tales derechos a la mera reparación pecuniaria.

3. Es necesario unificar los precedentes en materia de parte civil, como quiera que existen diferencias sustanciales en el tratamiento que recibe la parte civil dentro del proceso penal militar y la que recibe en la jurisdicción penal ordinaria (sentencias T-275/94, T-443/94). Tres son los 
precedentes constitucionales directamente relevantes que la Corte ha sentado en el campo de la justicia penal militar:

Primer Precedente: encontramos la sentencia C-740 del 2001, la Corte condicionó la constitucionalidad de una disposición que regulaba el traslado para alegar a determinados sujetos procesales dentro del procedimiento especial, regulado por el artículo 579 del Código Penal Militar y Ley 522 de 1999 en la cual no se incluía de manera expresa a la parte civil. Para ese entonces la Corte se expreso de la siguiente manera:

[...]...No debe olvidarse en efecto que dentro del procedimiento penal militar, el resarcimiento de perjuicios se reconoce claramente como un derecho de las personas afectadas por el hecho punible, pero que deberá obtenerse ante la jurisdicción en lo contencioso administrativo.......]

[...]...Es decir que dentro del proceso penal militar la actuación de la parte civil se establece de manera precisa, limitando su actuación al impulso procesal para contribuir a la búsqueda de la verdad de los hechos y que el tema del resarcimiento de perjuicios se concentra en la jurisdicción de lo contencioso administrativo, excluyendo expresamente la competencia de la justicia penal militar en este campo... [...]

[...]... De la lectura de este artículo se desprende que la Corte en el caso que la parte civil se haya constituido, de acuerdo con lo dispuesto en los artículos 305 a 310 de la ley 522 de 1999, podrá solicitar pruebas, así como impugnar la providencia que las decrete, pues ha de entenderse que el inciso segundo del artículo 579, al señalar que se trasladará a las partes que soliciten pruebas incluye a la parte civil, si ésta se ha constituido dentro del proceso... [...]

Segundo Precedente: En la concepción constitucional de los derechos de la víctima dentro del proceso penal militar, se encuentra en la sentencia C-1149 del 
2001, donde la Corte señaló que los derechos de la parte civil no se limitaban exclusivamente a la búsqueda de una reparación económica. La Corte abordó el estudio de los artículos 107 y 321 del Código de Procedimiento Penal Militar, que regulan la titularidad de la acción indemnizatoria y los fines de la construcción de la parte civil dentro del proceso penal militar, expresando lo siguiente:

[...]...El fin de la administración de justicia es hacer efectivos los derechos materiales de las personas, y los procedimientos tienen que servir para hacer efectivos en este caso, los derechos de las víctimas y perjudicados con el hecho punible no sólo a la reparación del daño, sino también a conocer la realidad de los hechos mediante la investigación respectiva a través del proceso penal y a que se haga justicia sancionando a los infractores... [...]

[...]...El derecho de las víctimas o perjudicados con el ilícito penal al acudir al proceso penal, comprenden tres derechos importantes y que deben ser garantizados por igual dentro del respectivo proceso:
a. Derecho a saber la verdad de los hechos
b. Derecho a la justicia
c. Derecho a la reparación del daño... [...]

Tercer Precedente: Se encuentra en la sentencia SU-1184 del 2001 (Sentencia SU-1184 de 2001) donde la Corte estudió una demanda de tutela interpuesta por la parte civil contra la decisión de la Sala Disciplinaria del Consejo Superior de la Judicatura, que dejó en manos de la Justicia Penal Militar el juzgamiento de un general por los hechos ocurridos en Mapiripán; con respecto a esto la Corte ha señalado:

[...] Las víctimas de los hechos punibles no tienen un sólo interés patrimonial, sino que comprenden el hecho a que se reconozca el derecho a saber la verdad y a que se haga justicia. El saber la verdad implica el derecho a que se determine la 
naturaleza, condiciones y modo en que ocurrieron los hechos y a que se determinen los responsables de tales conductas. El derecho a que se haga justicia o derecho a la justicia implica la obligación del Estado a investigar lo sucedido, perseguir a los autores $y$, de hallarlos responsables, condenarlos. De ahí que ostenten la calidad de sujetos procesales....[...]

[...]...En directa relación con lo anterior, debe entenderse que el complejo del debido proceso -legalidad, debido proceso en sentido estricto, derecho de defensa y sus garantías y el juez natural- se predican de igual manera para la parte civil. En punto al derecho a la justicia y a la verdad, resulta decisivo establecer si un hecho punible atribuido a un militar es un acto relacionado con el servicio, pues la responsabilidad derivada de la existencia o no de la mencionada relación será distinta. Así mismo, el primer efecto para conocer la verdad de lo acaecido y establecer quiénes son los responsables depende, en buena medida, de que se determine si el acto reunía dichas calidades. Así, la Corte estima que le asiste a la parte civil un interés -derecho- legítimo en que el proceso se tramite ante un juez natural........]

Estas diferencias, entre la doctrina de la parte civil en la jurisdicción penal ordinaria que restringía sus derechos a la búsqueda de una reparación económica, y la jurisprudencia reciente dentro del proceso penal militar que reconoce también sus derechos a la verdad y a la justicia, hacen necesario que la Corte unifique su jurisprudencia en esta materia para promover el derecho de igualdad.

Cuarto Precedente: Se justifica que se cambie la doctrina de la Corte fijada en la Sentencia C-293 de 1995. En dicho documento, la opinión de la Corte estaba fuertemente dividida, una posición como la plasmada en la sentencia 293/95, no tiene una vocación clara de permanencia ni puede generar la misma expectativa de estabilidad que cuando un fallo es unánime. 
Ahora bien, la Corte se ha pronunciado dentro de un contexto de tránsito legislativo en materia de procedimiento penal, puesto que han sido expedidas dos reformas integrales que se han traducido en un nuevo código de procedimiento penal y además, en un nuevo código de procedimiento penal militar. En efecto, la expedición de los nuevos códigos penal (ley 599 de 2000), de procedimiento penal (ley 600 del 2000) y penal militar (ley 522 de 1999), iniciaron una etapa de transición en el régimen penal. Ello conduce a que la confianza en la reiteración de la doctrina sentada por la Corte habida cuenta de la legislación a ese momento histórico vigente en 1995, no ha podido ser considerada fincada en la estabilidad del régimen actual dado que, el cambio legislativo fue de tal magnitud que se materializó en la expedición de nuevos códigos de procedimiento penal enmarcados por una política criminal orientada en parte, hacia la protección de los derechos humanos.

Los precedentes señalados, permiten afirmar que la visión de la parte civil solo interesada en la reparación económica debe ser abandonada. La víctima de un delito y los perjudicados por éste, tienen derecho a participar en el proceso penal no sólo para obtener el resarcimiento pecuniario, sino también para hacer efectivos sus derechos a la verdad y a la justicia; incluso, pueden intervenir con la única finalidad de buscar la verdad y la justicia, sin que se les pueda exigir demostrar un daño patrimonial o una pretensión de esta naturaleza. Así, la parte civil es un sujeto procesal en sentido pleno.

Esta concepción de la parte civil tiene trascendencia en la definición y alcances de la participación de las víctimas o perjudicados durante la investigación preliminar, así como dentro del proceso penal, y es pertinente señalar que también tiene implicaciones tanto en materia de los recursos que puedan interponer contra decisiones que puedan afectar sus derechos a la verdad y a la justicia, como respecto a la necesidad de que las providencias que puedan menoscabar sus derechos sean conocidas oportunamente por la parte civil para poder 
controvertirlas. Por ende, está legitimada, por ejemplo, para impugnar decisiones que conduzcan a la impunidad o que no realicen justicia.

En este orden de ideas, un precedente adicional en la jurisprudencia de la Corte Constitucional con ocasión de un pronunciamiento referente al principio de oportunidad y la desmovilización de los grupos insurgentes en Colombia mediante la sentencia C-936/2010, al pronunciarse sobre la exequibilidad del artículo 17 de la ley 1312 del 2009, en el marco del proceso de justicia transicional que vive Colombia.

Antes de continuar, es necesario definir lo que dentro de nuestra legislación se entiende por "Principio de Oportunidad", conforme al párrafo segundo del artículo 10. modificado por la el artículo 323 de la ley 906 de 2004, que lo define como la "facultad constitucional que le permite a la Fiscalía General de la Nación, no obstante que existe fundamento para adelantar la persecución penal, suspenderla, interrumpirla o renunciar a ella, por razones de política criminal, según las causales taxativamente definidas en la ley, con sujeción a la reglamentación expedida por el Fiscal General de la Nación y sometido a control de legalidad ante el Juez de Garantías".

La Corte Constitucional mediante sentencia anteriormente señalada, declara la inexequebilidad del artículo 17 de la ley 1312 del 2009, que en su tenor literal establece que, "Al desmovilizado de un grupo armado organizado al margen de la ley que en los términos de la normatividad vigente haya manifestado con actos inequívocos su propósito de reintegrarse a la sociedad, siempre que no haya sido postulado por el Gobierno Nacional al procedimiento y beneficios establecidos en la Ley de Justicia y Paz (975 de 2005), y no cursen en su contra investigaciones por delitos cometidos antes o después de su desmovilización con excepción de la pertenencia a la organización criminal, que para efectos de esta ley incluye la utilización ilegal de uniformes e insignias y el porte ilegal de armas y municiones". 
En esta sentencia, la Corte examinó si la causal de aplicación del principio de oportunidad acusada desconoce los derechos de las víctimas a la verdad, la justicia y la reparación, derivados de una interpretación sistemática de los artículos 1, 2, 12, 93 y 229 superiores en consonancia con los artículos 1, 2, 8 y 25 de la Convención Americana sobre Derechos Humanos; de tal suerte que, la "ley 1312 de 2009 sin establecer elementos de justicia, verdad y reparación a las víctimas, autoriza a la Fiscalía y a la Rama Judicial a renunciar a su obligación de investigar y juzgar a los desmovilizados por crímenes respecto de los cuales existe un imperativo internacional de investigar y juzgar, y en donde la impunidad resulta inadmisible" (Sentencia C-936/2010).

"En ese sentido, el precepto acusado no se inscribe dentro de un acuerdo político de reconciliación que conlleve cierta flexibilización de los principios que dominan el ejercicio de la función judicial, lo cual permite un modelo de justicia transicional. En esencia, se trata de una adición al proceso que se aplica para impartir justicia ordinaria, que de manera injustificada introduce un trato privilegiado a un grupo de destinatarios de la acción penal".

Así mismo, advierte la Corte, "que aún en situaciones de justicia transicional, la comunidad internacional ha admitido la importancia de alcanzar objetivos sociales de paz, pero ha hecho énfasis en que estas circunstancias de transición no pueden conducir a un relajamiento de las obligaciones internacionales de los Estados en el compromiso universal de respeto a la dignidad y a los derechos humanos. Al mismo tiempo, la comunidad internacional ha admitido que la justicia transicional es una forma especial de administración de justicia para situaciones de tránsito a la paz, pero no ha cedido en su exigencia de que las violaciones a los derechos fundamentales sean investigadas, enjuiciadas y reparadas, y los autores de las mismas contribuyan a identificar la verdad de los delitos cometidos y reciban en todo caso, algún tipo de sanción". 
Para la Corte, como quiera que los fines de una justicia transicional son específicos y muy distantes de aquellos que persigue la administración de justicia ordinaria, resulta arbitrario introducir dentro del modelo de justicia orientado a desarrollar la política criminal del Estado, un elemento que excluye a ciertos sujetos del ámbito de la justicia y justificar tal exclusión con un discurso de justicia hacia la paz.

En segundo lugar, la Corte estableció que la disposición legal demandada no respetaba los límites constitucionales para la aplicación del principio de oportunidad dado que, configura una causal que desborda la filosofía, los propósitos y el alcance del principio de oportunidad previsto en el artículo 250 de la Constitución Política, como una manera excepcional de renunciar, interrumpir o suspender la acción penal, dentro de un modelo de justicia ordinaria, regido por el principio de legalidad. Recordó que "si bien el legislador goza de una amplia potestad legislativa para regular la aplicación del principio de oportunidad, la jurisprudencia de esta Corporación ha señalado que debe respetar ciertos límites constitucionales al momento de configurar las causales que permiten su aplicación, los cuales han sido precisados en la sentencia C-095/07, a saber:

i. $\quad$ La vigencia de un orden justo;

ii. La dignidad humana, en cuanto debe respetar los compromisos internacionales en materia de acceso a la justicia para la protección de los derechos humanos y la reparación a las víctimas de graves violaciones;

iii. El principio de legalidad, con base en el cual está vedado establecer causales ambiguas o vagas, que le impide conocer con certeza al ciudadano en qué casos y bajo qué condiciones, el órgano investigador puede acudir ante el juez de control de garantías a pedir su aplicación". 
La Corte encontró que la causal establecida en el numeral 17 del artículo $2^{\circ}$ de la Ley 1312 de 2009, vulnera el postulado del orden justo que el Estado debe promover, habida cuenta que establecía una renuncia unilateral a investigar, sin que de otro lado se introduzca requisitos que satisfagan las exigencias de justicia, de verdad o de reparación. Esta laxitud en la regulación, vulnera la dignidad y los derechos de las víctimas protegidas por diversos instrumentos internacionales que obligan al Estado colombiano a investigar y juzgar en materia de graves violaciones de derechos humanos. Así mismo, la Ley 1312 de 2009, introducía una causal vaga y ambigüa para la aplicación excepcional del principio de oportunidad, violatoria del postulado de legalidad que lo rige.

A lo anterior se agrega "que el principio de oportunidad, como instrumento de la política criminal ordinaria del Estado, parte del deber de la persecución penal. Por ello, la renuncia a ese deber de persecución debe estar fundada en criterios de: insignificancia, interés de la víctima, formas alternativas de satisfacción de intereses colectivos y colaboración con la justicia. A ninguno de estos criterios, responde la causal que se cuestiona". Y, agrega de manera muy sabia la Corte Constitucional haciendo referencia a los procesos transicionales que "...la comunidad internacional ha admitido que la justicia transicional es una forma especial de administración de justicia para situaciones de tránsito a la paz, pero no ha cedido en su exigencia de que las violaciones a los derechos fundamentales sean investigadas, enjuiciadas y reparadas y los autores de las mismas contribuyan a identificar la verdad de los delitos cometidos y reciban en todo caso, algún tipo de sanción...". Esto último garantiza y contribuye a la no repetición de los mismos hechos violentos, dado que así, se reconstruye la memoria histórica.

\section{El precedente jurisprudencial en Colombia}

En nuestro ordenamiento jurídico es indudable la influencia que ejerce la jurisprudencia de la Corte Constitucional desde 1991, fecha en la cual se reconstituyó el país por medio de una Asamblea Nacional Constituyente, periodo histórico en el que surge la Corte Constitucional como entidad suprema de 
administración de justicia en el naciente estado social de derecho, en lo referente a la constitucionalidad del mismo. Ahora bien, dentro de la doctrina jurídica formada por el conjunto de sentencias que a la fecha la Corte ha emitido, se observan una serie de desarrollos jurisprudenciales que se han venido constituyendo en prácticas generalizadas frente a la interpretación de una determinada norma; dichas prácticas pasan a ser fuente de derechos y obligaciones, en pro de salvaguardar la constitucionalidad del mencionado estado social de derecho.

De tal suerte que "al reconocerse la Constitución como la norma de normas con plena efectividad jurídica y al gozar de una Corte propia que salvaguarda su integridad, no puede un administrador de justicia despreciar sus argumentos arguyendo que sólo está sometido al "imperio de la ley", pues la constitución es la ley por excelencia y lo mínimo que se espera de las decisiones de quien está facultado exclusivamente para interpretarla, es que los precedentes que llegaren a conformar doctrina constitucional sean de obligatorio cumplimiento" (Jurista Eduardo Pilonieta Pinilla, en su posesión en la Academia Colombiana de Jurisprudencia).

Es claro que los precedentes y líneas jurisprudenciales de la Corte Constitucional tienen pleno valor vinculante para los jueces de la República, dado que constituyen verdaderas fuentes de derechos y obligaciones en todo el territorio nacional. Siendo así, el respeto y cambio de la jurisprudencia, la Corte Constitucional debe pasar por cuatro requisitos establecidos por la misma Corte refiriéndose a los precedentes jurisprudenciales en la Sentencia de Unificación 047 de 1999, en la cual ha manifestado que:

[...]...el respeto a los precedentes cumple funciones esenciales en los ordenamientos jurídicos, incluso en los sistemas de derecho legislado como el colombiano. Por ello, tal y como esta Corte lo ha señalado, todo tribunal, y en especial el juez constitucional, debe ser consistente con sus decisiones previas; 
ver, por ejemplo, entres otras, las sentencias T-13 de 1995 y C-400 de 1998, al menos por cuatro razones de gran importancia constitucional, como son las siguientes:

i. En primer término, por elementales consideraciones de seguridad jurídica y de coherencia del sistema jurídico, pues las normas si se quiere que gobiernen la conducta de los seres humanos, deben tener un significado estable, por lo cual las decisiones de los jueces deben ser razonablemente previsibles.

ii. En segundo término, y directamente ligado a lo anterior, esta seguridad jurídica es básica para proteger la libertad ciudadana y permitir el desarrollo económico, ya que una caprichosa variación de los criterios de interpretación pone en riesgo la libertad individual, así como la estabilidad de los contratos $y$ de las transacciones económicas, pues las personas quedan sometidas a los cambiantes criterios de los jueces, con lo cual difícilmente pueden programar autónomamente sus actividades.

iii. En tercer término, en virtud del principio de igualdad, puesto que no es justo que casos iguales sean resueltos de manera distinta por un mismo juez.

iv. $Y$ finalmente, como un mecanismo de control de la propia actividad judicial, pues el respeto al precedente, impone a los jueces una mínima racionalidad y universalidad ya que los obliga a decidir el problema que les es planteado de una manera que estarían dispuestos a aceptar otro caso diferente pero que presente caracteres análogos. Por todo lo anterior, es natural que en un Estado de derecho, los ciudadanos esperen de sus jueces que sigan interpretando las normas de la misma manera, por lo cual resulta válido exigirle un respeto por sus decisiones previas”... [...]( Sentencia de Unificación SU-0047 de 1999). 
Desde una perspectiva de interpretación sociológica, los textos jurisprudenciales son fiel reflejo de las necesidades sociales del momento en una sociedad, de tal manera que el juez debe hacer justicia en el caso concreto pero de conformidad con el derecho vigente, por lo cual tiene el deber mínimo de precisar la regla general o el principio que sirve de base a su decisión concreta ( Sentencia SU 047 de 1999)

\section{CONCLUSIONES}

La paz de un pueblo sólo se puede construir en la medida en que las víctimas de los genocidios, crímenes de guerra y delitos de lesa humanidad cometidos por los grupos paramilitares y paraestatales (FARC, ELN) en el marco del conflicto interno que cumple ya cuatro décadas, tengan un legítimo derecho a conocer la verdad de los hechos ocurridos, a que se haga justicia y que se les brinde una reparación moral y económica; así mismo, el Estado tiene el legítimo derecho a que se prevenga la repetición de hechos de esa misma naturaleza, con el sano propósito de no repetir la historia nefasta y de otra parte reconstruir la memoria histórica, fundamental para edificar la paz sostenible de la nación sobre bases sólidas, producto del desarrollo y evolución de un país.

Para concluir, estimo muy acertado mencionar las siguientes líneas extraídas de la exposición de motivos de la Ley de Justicia y Paz: "Sólo sobre la base de la verdad de los crímenes cometidos por agentes del Estado o particulares vinculados al paramilitarismo, como financiadores, planificadores, auspiciadores, autores intelectuales, asesores nacionales y extranjeros, será posible satisfacer las exigencias elementales de la justicia y crear condiciones indispensables para alcanzar una efectiva reconciliación nacional. Sólo el conocimiento de la verdad, rehabilitará en el ámbito público la dignidad de las víctimas, facilitará a sus familiares y deudos la posibilidad de honrarlas como corresponde y permitirá reparar de forma integral los daños causados por la violación a todos sus derechos". Como se expresa en la exposición de motivos de Proyectos de la Ley 
de Justicia y Paz, Número 180 de 2004, Senado de la República de Colombia, por la cual se dictan normas sobre verdad, justicia, reparación, prevención, publicidad y memoria para el sometimiento de los grupos paramilitares que adelanten diálogos con el gobierno. (2005)

\section{REFERENCIAS BIBLIOGRÁFICAS}

- A., T. y. (1982). Los Derechos Humanos. Madrid, España: Tecnos.

- Asamblea General de las Naciones Unidas, Res. 217 A (III), O. D. (1948). Declaración Universal de Derechos Humanos, p.71 (1948). (pág. 71). ONU.

- Agostinho, S. (1996). Um estudo crítico da história . Revista da Universidade de São Paulo , 31, 52- 179.

- Alexy, R. (1997). Precedent in the Federal Republico f Germany" en Interpreting Precedent, MacComick D.N. \& Summers R.S. (eds.) . Alemania: Editorial Darmouth.

- Antonio, T. J. (1995). Derechos Humanos y Derecho Internacional. Buenos Aires, Argentina: Heliosta.

- Aquino, S. T. Questões sobre a verdade. In: Os pensadores.

- Asamblea General Naciones Unidas .Res. 2200A (XXI). (1966). Pacto Internacional de Derechos Civiles y Políticos. En ONU (Ed.), Pacto Internacional de Derechos Civiles y Políticos . 16, págs. 999 UNTS 171, entrada en vigor 23 de Marzo de 1976. Articulo 2.1. AG.res. 2200A (XXI).

- Barahona De Brito, A. A. (2001). Las políticas hacia el pasado: juicios, depuraciones, perdón y olvido en las democracias (Vol. 1). (Istmo, Ed.)

- Berger, V. (1991). Jurisprudence de la Cour Européene des droits de I’homme. (T. edición, Ed.) Editorial Sire.

- Bernal García, J. M. (2003). Metodología de la investigación jurídica y socio jurídica. (C. d. Facultad de Ciencias Jurídicas y Sociales, Ed.) Tunja, Boyaca, Colombia: Editorial de Universidad de Boyacá.

- Bernal-Meza, R. G. (1991). Claves del nuevo orden mundial. Buenos Aires. 
- Bertalanffy, I. V. (1994). Teoría General de los Sistemas. Fondo de Cultura Economica.

- Bobbio, N. (1997). Teoría General del Derecho. Temis.

- Bobbio, N. (1990). Contribución a la Teoría del Derecho. Debate.

- Caso Aksoy c. Turquía, Sentencia (Corte Europea de Derechos Humanos 18 de Diciembre de 1996).

- Caso Barrios Altos, Sentencia (Chumbipuma Aguirre y otro c. Perú) (Corte Interamericana de Derechos Humanos 2001 de Marzo de 2001).

- Caso Genie Lacayo., Serie C No. 35. (29 de Enero de 1997).

- Caso Lamy c. Bélgica, Sentencia (Corte Europea de Derechos Humanos 30 de Marzo de 1989).

- Caso Suárez Rosero, Serie D No. 30. (Corte Interamericana de DDHH 12 de Noviembre de 1997).

- Caso Velázquez Rodríguez, Fundamento 176 (Corte Interamericana de DDHH 29 de Julio de 1988).

- Chomsky, N., \& Dieterich, H. (1998). La Aldea Global (Vol. 1). (3. Edicion, Ed.) Txalaparta, Tafalla.

- Colombia, S. d. (2004-2005). Exposición De Motivos De Proyectos De La Ley De Justicia y Paz, Senado de la República de Colombia. Por La Cual Se Dictan Normas Sobre Verdad, Justicia, Reparación, Prevención, Publicidad y Memoria Para El Sometimiento Grupos Insurgentes. Bogotá D.C.: Congreso de la República de Colombia.

- Convención Americana DDHH - Reimprimida Corte Interamericana. (Julio de entrada en vigor 18 de Julio de 1978). Convención Americana de Derechos Humanos. (S. s. 123, Ed.) (36), pág. 123.

- Correas, C. I. (2008). Los derechos humanos y el pensamiento actual (2० ed.). Buenos Aires, Argentina.

- Cruz, P. M. (2009). Soberanía y transnacionalidad: antagonismos y consecuencias. Revista Jurídica Jurídica (6), 97-120.

- Delmas-Marty, M. (1995). Procédures pénales d’Europe, Presses Universitaires de Frances. 
- El libro de Ruti G. Teitel. (2000). Transsitional Justice.

- Emerson, R. W. (1999). El espíritu de la naturaleza. Buenos Aires, Argentina: Errepar.

- Evans, P. i. (1997). The Eclipse of the State - Reflections on Stateness in an Era of Globalization (Vol. 50). Princeton, Estados Unidos.

- Garantías judiciales en estados de emergencia, Serie A, No.9, Párr. 24 (Corte Interamericana de Derechos Humanos 06 de Octubre de 1987).

- Herrera, J. C. (2010). Reconciliación y justicia transicional: opciones de justicia, verdad, reparación y perdón. Bogotá D.C. -Colombia.

- Kelsen, H. (1988). Teoría General del Derecho. UNAM.

- Joinet, R. E. Relatoría sobre la impunidad de perpetradores de violaciones de los Derechos Humanos. (Vols. Un Doc.E/sub.2/19936, 1). (O. D. Unidas, Ed.) ONU.

- Jr, D. W. (1998). International Tuth Commissions and Justice; Luc Huyse, "Justice after Transition: On the Choices sucesor elites makes in dealing with the past", en Transitional Justice ., $1^{\circ}$, págs. 326-349.

- Klauss, S. (1987). Derecho del Estado de la República Federal Alemana. Madrid, España: Centro de estudios Constitucionales.

- Manuel, C. U. (1993). justicia constitucional, derecho comparado . Banco de la República. Banco de la República.

- Medina, L. (2004). Teoría Impura del Derecho. Temis.

- Méndez, J. E. (1988). "The Rigth to Truth", en Reining in Impunity for International Crimes and Serious Violations of Fundamental Rigth: Proccedings of the Siracusa Conference.

- Monde, D. L. (09 de Abril de 2002). El proceso contra Richard Durn, el llamado "Asesino de Nantterre". El proceso contra Richard Durn, el llamado "Asesino de Nantterre".

- Naciones Unidas. Protocolo Adicional I de 1977 a los Convenios de Ginebra del 12 de Agosto de 1949.

- OEA. (1948). Declaración Americana de los Derechos y Deberes del Hombre, OAS Res. XXX, aprobada en la Novena Conferencia Internacional 
Americana (1948),. Organización De Estados Americanos. CostaRica: Reimprimido en Documentos Básicos Concernientes a los Derechos Humanos en el Sistema Interamericano, OEA/Ser.L.V.

- Olano, C. A. (2000). Derecho Constitucional e Instituciones Políticas. Librería el Profesional.

- Paul Mccold Y Ted Wachtel, I. F. (2003). En Busca De Un Paradigma: Una Teoria Sobre Justicia Restaurativa Internacional. Revista Forum.

- Perez, P. M. (2001). Filosofía da Política Jurídica. Itajaí: Univali.

- Pizzi, W. T. (1996). "Crime Victims in German Courtrooms: A Comparative Perspective on American Problems" 32, stanford Journal of International Law, .

- Poesias, P. F. (1996). Poesias. P. Alegre:L\&PM.

- Pradel, J. (1995). (1995), Droit Pénal Comparé, Editorial Dalloz, p. 532 a 535.

- Protocolo Adicional I de 1977 a los Convenios de Ginebra del 12 de Agosto de 1949. Naciones Unidas.

- Regla, J. A. (2006). Curso De Teoría De Las Fuentes y Del Ordenamiento Jurídico , (Clase 421). (2. a. Itajaí, Ed.) CPCJ/UNIVALI.

- Relator Especial Louis Joinet. Ver Organización de Naciones Unidas. Subcomisión para la Prevención de la Discriminación y la Protección de las Minorías. Sobre la Impunidad de Perpetradores de Violaciones a los Derechos Humanos. Relator Especial Louis Joinet, (1993), UN Doc. E/CP.4/Sub.2/1993/6. ONU.

- Richard S. Frae Pradel, J. (1990). "Comparative Criminal Justice as a Guide to American Law Reform: How Do the French Do It, How Can We Find Out, and Why Shuold We Care" (Vol. 78 Cal.I.Rev.542). (E. Dalloz, Ed.)

- Rolla, G. (2000). Manuale Di Diritto Pubblico Torino. Roma - Italia: G. Giappichelli Editore.

- Rousseau, J. J. (2005). 1. Rousseau, Juan Jacobo, El Contrato Social de Juan Jacobo, (2005) Siglo XVII, Edición Digital,. Edición Digitahttp://books.google.com.co/books? 
- Sanchez, M. I. (1992). La sociedad Poscapitalista. Buenos Aires Suramerica, Argentina.

- Schäfer, J. G. (2002). Direitos fundamentais: proteção e restrições. Porto Alegre: Do Advogado. ., 2001. p. 104. Sao Paulo: Malheiros.

- Stpephens, B. (1997). Conceptualizing Viollence: Present and Civil Wrongs at Home and Abroad: Old Problems and New Paradigms:Do Tort Remedies Fit the Crime. Kosovo-Albania.

- Tocora Luis Fernando. (1993). Control Constitucional y Derechos Humanos. Santa Fe De Bogotá D.C., Colombia: Librería Del Profesional.

- Uprimny, R. (2006). ¿Justicia transicional sin transición? Verdad, Justicia y Reparación Para Colombia. Colección Ensayos y Propuestas , 14.

- Vigo, R. L. (2004). Interpretación constitucional ( $2^{\circ}$ ed.). Abeledo Perrot. 